\title{
Mimosa pudica (Lajwanti) Accelerates Repair and Regeneration of Deep Dermal Excision Wound in Swiss Albino Mice
}

\begin{abstract}
The present study was carried out to evaluate the wound healing potential of the ethanol extract of the whole lajwanti plant on the deep dermal excision wounds in mice. The dried powder of whole plant was sequentially extracted in petroleum ether, chloroform, ethanol and water. Different doses of dried ethanol extract were orally administered in mice for six consecutive days before creation of the rectangular deep dermal excision wound. The wound contraction was recorded daily followed by monitoring the animals for complete healing of wounds. The ability of ethanol extract to influence the collagen, hexosamine, DNA and nitric oxide syntheses and glutathione, catalase, superoxide dismutase and lipid peroxidation was also determined at day7 and 12 post wounding. The administration of $50,100,150$ and $200 \mathrm{mg} / \mathrm{kg}$ body weight of ethanol extract of lajwanti increased the wound contraction in a dose dependent manner accompanied by the reduction in the mean wound healing time which was shortest (18 days) for $200 \mathrm{mg} / \mathrm{kg}$ when compared to untreated control (24 days). The ethanol extract of lajawanti increased the synthesis of collagen, hexosamine and DNA and reduced the nitric oxide synthesis on 7 and 12 days post wounding. The glutathione concentration and the activities of catalase, and superoxide dismutase also increased in a dose dependent manner followed by the alleviation of lipid peroxidation. The present study demonstrates that lajwanti enhanced wound healing by increasing the synthesis of collagen, hexosamine, and DNA as well as glutathione concentration and the activities of catalase, and superoxide dismutase enzymes. It also reduced nitric oxide synthesis and lipid peroxidation.
\end{abstract}

Keywords: Mice; Mimosa pudica; wound healing; Collagen; Hexosamine; Antioxidants and lipid peroxidation

\author{
Research Article \\ Volume 9 Issue 2 - 2017 \\ Ganesh Chandra Jagetia*, Rokin Lyngdoh, \\ Lalramchuana and Bijoy Krishna Borah \\ Department of Zoology, Mizoram University, India
}

*Corresponding author: Ganesh Chandra Jagetia, Professor, Department of Zoology, Mizoram University, Aizawl-796 004, india, Tel: 091-389-2330724; 2330227; Email: gc.jagetia@gmail.com

Received: March 30, 2017 | Published: November 01, 2017

\section{Introduction}

The traditional medicine has originated with the infliction of diseases in the human beings as the natural products including plants were in the easy reach of humans. The humans have depended on plants and other natural products for their healthcare since time immemorial. The herbs and natural products continue to play a major role to treat several diseases even during the modern era. According to an estimate by World Health Organization $80 \%$ of the world's population including developed and developing countries use plants and natural products for their healthcare [1]. The pharmacopeias were dominated by use of plants and natural product 200 years ago. However, the use of plants as medicine declined with the establishment of pharmacology in the therapeutics and development of several chemical synthetic drugs [2]. Despite the availability of modern medical system the majority of the word population relies on medicinal plants because plants have been tested for several generations for their use as medicine to treat different ailments and the use of medicinal plants has been considered non-toxic at the dosage that are administered for the treatment of different ailments. This may be because of their biologic origin in contrast to modern synthetic drugs, which are toxic even at their effective dosages. The importance of medicinal plant can be realized by the fact that usage of herbal medicine has been constantly increasing in the general population of USA and its use increased as much as $380 \%$ from a mere 2.5 to $12.1 \%$ between 1990 - 1997 [3].

The toxicological, therapeutic effects of plants and minerals in the Indian subcontinent have its origin in prehistoric times, where plants and minerals have been used successfully to treat various disorders and the Indian system of traditional medicine the Ayurveda is at least 5000 year old and its texts give a good account of various diseases and their treatment. The interest in allopathic medicine also declined due to severe side effects and overuse of the modern drugs. The popularity of the use of traditional medicine among humans has resulted in the resurgence of plants as medicine during the last 20 years. It is also known that many of the modern drugs have their origin in plants before they were chemically synthesized [4]. The beauty of plants as medicine lies in the fact that they synthesize several chemicals, some of them may be active as medicine/s, whereas others may act as detoxifying agents when a whole plant product is given in comparison to an isolated compound though may be effective but could produce adverse side effects on human health [5].

The wounds are of common occurrence and it will be difficult to find any individual who did not suffer from wound injuries. The 
wound can result from physical or chemical agents and the wound can be considered as a disruption of the protective function of the skin and a breach in the epithelium with or without the loss of muscle, bone, nerves, etc. [6]. The wound healing is a complex process that involves continuous cell-cell and cell-matrix interactions. The wound healing proceeds in three overlapping phases: inflammation ( $0-3$ days), cellular proliferation (3-12 days) and remodeling (3-6 months) [7-9]. It has been reported that only $1-3 \%$ of drugs listed in Western pharmacopoeia are intended for use in the skin and for wound repair [10]. Both traditional and Western systems of medicine for wound healing suffer from the lack of resources and awareness. Wound healing constitutes a major problem due to the high cost of therapy and the presence of unwanted side effects [11] which indicates the need to find newer paradigms for wound healing.

The Mimosa pudica (lajwanti) is a creeping annual or perennial herb of the pea family fabaceae. The Ayurveda texts describe lajwanti as tikta (bitter) and kashaya rasa (astringent) in taste and by nature it is considered sheetha (cold). Its use balances kapha, and pitta. It is described as antiasthmatic, stimulant, painkilling and antidepressant remedy in Ayurveda. The whole plant is crushed and used to relive itchiness and itch related diseases. The roots of lajwanti are used to treat leucoderma, angiopathy, metropathy, ulcers, dysentery, swellings, jaundice, bronchial asthma, small pox, strangury, and fevers. Its leaves are useful in hydrocele, hemorrhoids, fistulous withers, scrofula, pinkeye, cuts and bleeds.

The whole plant of lajwanti is used to cure dropsy, rheumatoid arthritis, myodynia and uterine tumors in Aurvedic medicine [12]. All parts of this plant are considered to possess medicinal properties and it is used in the treatment of biliousness, leprosy, dysentery, vaginal and uterine complaints, inflammations, burning sensation, fatigue, asthma, leucoderma, and blood diseases [13]. Lajavanti has been reported to be active against diarrhea (athisaara), amoebic dysentery (raktaatisaara), bleeding piles, and it also arrests bleeding [12]. Different extracts of lajavanti have been found to possess antinociceptive, antiandrogenic, antidiabetic, antibacterial, antiinflammatory, antifungal, anticonvulsant, antioxidant, antitumor, antiulcer, antihyperglycemic, immunomodulatory, antifertility, diuretic, hepatoprotective, and wound healing activities $[12,14]$. It has also been credited to possess antidiabetic, antifertility, antimalarial, antidepressant, antidiarrheal, and antivenomic activites [15]. Mimosa pudica leaf extract has been reported to protect mice against pentylentetrazol and strychnine-induced seizures and $\mathrm{N}$-methyl-D-aspartate-induced turning behavior in mice [16]. The acute toxicity studies of chloroform and methanol extracts up to $5 \mathrm{~g} / \mathrm{kg}$ orally did not cause any toxicity in mice [17]. The systematic studies on the use of ethanol extract of whole Mimosa pudica (lajwanti) plant on wound healing are lacking therefore the present study was designed to evaluate the effect of lajwanti on the deep dermal excision wound of mice.

\section{Materials and Methods}

\section{Chemicals}

Hydroxyproline (catalog No: H5534), chloramine-T (catalog No: C9887), deoxyribonucleicacid (catalog No: D4522), diphenylamine (catalog No: D2385), $\rho$ dimethylaminobenzaldehyde (catalog No: 42363-0250), thiobarbituric acid (TBA), naphthyl ethylene diamine dihydrochloride (NEDD) and sodium nitroprusside were procured from Sigma Aldrich Chemical Co., St. Louis, MO, USA, while carboxymethylcellulose (CMC), methanol, ethanol, trichloroacetic acid, sodium hydroxide, hydrochloric acid, sodium chloride, n-butanol, potassium dihydrogen phosphate, dipotassium hydrogen phosphate, sodium carbonate, sodium bicarbonate, ethylenediaminetetraacetic acid (EDTA), sulphanilamide, phosphoric acid and potassium chloride were supplied by SD fine-chemicals Ltd., Mumbai, India.

\section{Animal care and handling}

The animal care and handling were carried out according to the guidelines issued by the World Health Organization, Geneva, Switzerland and the INSA (Indian National Science Academy, New Delhi, India). Usually, 6 to 8 weeks old healthy male Swiss albino mice weighing 30-35g were selected from an inbred colony maintained under the controlled conditions of temperature $(25 \pm 2$ ${ }^{\circ} \mathrm{C}$ ), humidity (55-60\%) and 12 hours of light and dark cycle, respectively. The animals were housed in a sterile polypropylene cage containing paddy husk (procured locally) as bedding material. The animals had free access to standard rodent diet and water. All animal experiments were carried out according to NIH and Indian National Science Academy, New Delhi, India guidelines. The study was approved by the Institutional Animal Ethics Committee of the Mizoram University, Aizawl, India vide letter no. IAEC/4503.

\section{Experimental protocol}

The wound healing activity of ethanol extract of lajavanti was evaluated in the deep dermal excision wound created on mice dorsum according to the details given below and a total of 300 animals were used to complete all experiments.

\section{Preparation of extract}

The plant Mimosa pudica or lajwanti (family: Fabaceae) was identified and authenticated by the Department of Horticulture Aromatic and Medcinal Plants, Mizoram University, Aizawl, India. The non-infected whole plants were collected from the Mizoram University campus during the month of September to December. The plants were cleaned; shade dried and powdered using an electrical grinder. The powdered form of Mimosa pudica plant was sequentially extracted with petroleum ether, chloroform, ethanol and water using Soxhlet apparatus. The ethanolic extract was dried and stored in the refrigerator for further use. Henceforth the ethanol extract of Mimosa pudica will be called as MPE.

The wound healing potential of lajwanti was performed by dividing the animals into the following groups:-

a. CMC group: This group of animals was orally administered with $0.5 \%$ CMC consecutively for six days.

b. MPE group: The animals of this group were orallyadministered with MPE 50, 100, 150 and $200 \mathrm{mg} / \mathrm{kg} \mathrm{b}$. wt. for six consecutive days before the creation of full thickness deep dermal excision wounds. 


\section{Production of full-thickness skin wound}

The full thickness deep dermal excision wound was created on the dorsum of mice as described earlier [18]. Briefly, the fur of the dorsum of each animal was removed with a cordless electric mouse clipper (Wahl Clipper Corporation, Illinois, USA). The animals were anaesthetized using controlled anestheisa and the entire body was cleaned and decontaminated by wiping with 70 $\%$ ethanol. The cleared dorsal surface of the skin was marked with a sterile rectangular $(2.5 \times 1.5 \mathrm{~cm})$ acrylic stencil. A full thickness dermal wound was created by excising the full thickness skin flap in an aseptic environment under a vertical laminar flow apparatus using sterile forceps and scissors. Each wounded animal was housed in a separate sterile polypropylene cage until the termination of experiments.

The following studies were carried out:-

a. Wound Contraction: The wound contraction was determined daily by measuring the wound area on every day after wounding by using a transparent graph grid of $1 \mathrm{~cm}^{2}$ until the complete healing of the wound. The transparent graph grid (having 100 divisions of $1 \mathrm{~mm}^{2}$ ) was superimposed over the excision wound and each $1 \mathrm{~mm}^{2}$ that filled the wound length and width was counted. A minimum of three readings each (for length and width) was collected for each animal and the area was calculated by multiplying the mean length with the mean width of each wound. A minimum of 50 animals were used for this experiment.

b. Mean wound healing time: A separate experiment was performed to determine the mean wound healing time in mice receiving MPE or not, where grouping and other conditions were essentially similar to that described above, except that all the animals in each group were monitored regularly until complete healing of wounds and the day by which each wound healed completely was recorded. Mean of all healed wounds was calculated and expressed as mean wound healing time in days. Ten animals were used in each concurrent group and a total of 50 animals were used to complete the experiment.

c. Biochemical estimations: A separate set of experiments was conducted to study the effect of MPE on various biochemical profiles in the granulation tissues of the wounds treated or not with MPE. The granulation tissues were collected from regenerating excision wound/s on day 7 and 12 post wounding and stored at $-70{ }^{\circ} \mathrm{C}$ until analysis. 20 animals were used for each MPE dose and CMC group at each interval and a total of 200 animals were used to complete the whole experiment. The various estimations listed below were carried out:-

i. Collagen: As an indication of total collagen content, hydroxyproline concentration was determined as described earlier [19]. The weighed granulation tissues were hydrolyzed in $6 \mathrm{~N} \mathrm{HCl}$ for $3 \mathrm{~h}$ at $130{ }^{\circ} \mathrm{C}$, neutralized to $\mathrm{pH} 7$ with $2.5 \mathrm{~N}$ $\mathrm{NaOH}$ and diluted with Milli-Q water. The diluted solution was mixed with chloramine- $T$ reagent and incubated for $20 \mathrm{~min}$ at room temperature. Thereafter, freshly prepared $\rho$-dimethylaminobenzaldehyde (Ehrlich's reagent) solution was added and incubated for $15 \mathrm{~min}$ at $60^{\circ} \mathrm{C}$. The absorbance of each sample was measured at $550 \mathrm{~nm}$ using a double beam UV-visible spectrophotometer (Systronic, Ahmadabad, India). The amount of hydroxyproline was determined by comparing with the standard curve. Total collagen from hydroxyproline analysis was determined by multiplying with a factor of 6.94 . Collagen content of granulation tissues has been expressed as $\mathrm{mg} / \mathrm{g}$ dry tissue weight.

ii. Estimation of Hexosamine: Hexosamine contents of granulation tissues were estimated by the method of Elson and Morgan [20] with minor modifications. Briefly, weighed granulation tissues from five animals were hydrolysed with $6 \mathrm{~N} \mathrm{HCl}$ for $8 \mathrm{~h}$ at $98^{\circ} \mathrm{C}$, followed by neutralization to $\mathrm{pH} 7$ with $4 \mathrm{~N} \mathrm{NaOH}$ and dilution with Milli-Q water. The diluted solution was mixed with acetylacetone and heated up to $96^{\circ} \mathrm{C}$ for $40 \mathrm{~min}$. The mixture was cooled mixed with $96 \%$ ethanol followed by the addition of $\rho$-dimethylaminobenzaldehyde solution (Ehrlich's reagent). The solution was thoroughly mixed, kept at room temperature for $1 \mathrm{~h}$ and the absorbance was read at $530 \mathrm{~nm}$. The amount of hexosamine was determined by comparing with a standard curve.

iii. Deoxyribonucleic acid (DNA): Estimation of DNA gives an indication of cell proliferation and was measured by homogenizing the dry granulation tissues in 5\% TCA followed by centrifugation. The pellets were washed with $10 \%$ TCA, resuspended in $5 \% \mathrm{TCA}$, and incubated at $90{ }^{\circ} \mathrm{C}$ for $15 \mathrm{~min}$. The contents were centrifuged again and the resultant supernatant was used for the estimation of DNA by the method of Burton [21]. The DNA was hydrolyzed with $60 \%$ perchloric acid at $80{ }^{\circ} \mathrm{C}$ for $20 \mathrm{~min}$ followed by the addition of Burton's diphenylamine reagent followed by an overnight incubation at room temperature. Thereafter, 95\% ethanol was added and absorbance was read at $600 \mathrm{~nm}$ using a double beam UV-visible spectrophotometer. The amount of DNA was determined by comparing with the standard curve and has been expressed as $\mathrm{mg} / \mathrm{g}$ dry tissue weight.

iv. Nitric oxide (NO): The stable end products of nitric oxide biosynthesis were measured by estimating nitrite levels in the granulation tissue of wounds. The granulation tissues were homogenized in hypotonic saline and centrifuged. Nitrite concentrations were determined with Griess reagent [22]. Briefly, the supernatant was mixed with freshly prepared Griess reagent $(0.1 \%$ NEDD, $1 \%$ sulphanilamide and $5 \%$ phosphoric acid in a $1: 1: 1$ ratio), incubated at $37^{\circ} \mathrm{C}$ for $30 \mathrm{~min}$ and the absorbance was recorded at $543 \mathrm{~nm}$ using a double beam UVvisible spectrophotometer. Sodium nitrite was used as standard. Nitrite levels have been expressed in terms of $\mu \mathrm{M} / 100 \mathrm{mg}$ dry tissue weight.

v. Estimation of antioxidants: The glutathione (GSH), catalase, superoxide dismutase (SOD), and lipid peroxidation (LOO) in the regenerating wound granulation tissue were measured by preparing $10 \%$ homogenate in phosphate buffered saline.

vi. Protein estimation: Total estimation of protein contents in the granulation tissues of regenerating wound was done by the modified method of Lowry et al. The standard curve (absorbance versus concentration of protein) was prepared 
by using different concentration of bovine serum albumin $(0-$ $100 \mu \mathrm{g}$ ) and the standard sample was processed like that of test samples. The protein concentration of the test samples has been calculated with reference to the standard curve and the results have been expressed as mg protein/g tissue weight.

vii. Glutathione (GSH): GSH contents were determined by following the method of Moron et al. [23]. Briefly, after precipitation of proteins with 25\% TCA, the samples were centrifuged and the supernatant was collected. The supernatant was mixed with $0.2 \mathrm{M}$ sodium phosphate buffer pH 8.0 and $0.06 \mathrm{mM}$ DTNB and incubated for 10 minutes at room temperature. The absorbance of the sample/s was read against the blank at $412 \mathrm{~nm}$ in a UV-Visible Spectrophotometer and the GSH concentration has been calculated from the standard curve.

viii. Catalase activity: The catalase activity was estimated by the catalytic reduction of hydrogen peroxide [24]. Briefly, hydrogen peroxide was added to the granulation tissue homogenate and incubated at $37^{\circ} \mathrm{C}$. The decomposition of hydrogen peroxide was monitored at specific time intervals by recording the absorbance against the blank at $240 \mathrm{~nm}$ using a UV-VIS spectrophotometer.

ix. Superoxide Dismutase (SOD): The activity of SOD was determined by the method described by Ewing \& Janero [25]. Briefly, the cell homogenate was mixed with reagent consisting of phenazine methosulfate, nitroblue tetrazolium and NADH and incubated for $90 \mathrm{sec}$. at $30^{\circ} \mathrm{C}$ and the reaction was stopped by adding acetic acid and n-butanol. Blank was prepared by adding the reagent without the sample and incubated for $90 \mathrm{sec}$. at $30{ }^{\circ} \mathrm{C}$ and the reaction was stopped by adding acetic acid and n-butanol. The absorbance of sample was measured against the blank at $560 \mathrm{~nm}$ in a UV-VIS spectrophotometer. The percent inhibition was calculated by measuring the absorbance of blank without SOD enzyme and the sample as follows:-

\section{PI=Sample-Blank/Sample x100}

x. Lipid peroxidation (LO0): The lipid peroxidation was measured according to standard protocol [26]. Briefly, the homogenate was mixed with trichloroacetic acid (15\%), thiobarbituric acid $(0.8 \%)$, and butylated hydroxytoluene $(0.01 \%)$ in $0.25 \mathrm{~N} \mathrm{HCl}$ and incubated at $95{ }^{\circ} \mathrm{C}$ for $25 \mathrm{~min}$. The reaction mixture was allowed to cool to room temperature, centrifuged at $8,000 \mathrm{~g}$ and the supernatant was collected. The absorbance was recorded against the blank using a UVVIS spectrophotometer. The lipid peroxidation has been expressed as MDA nmols/mg protein.

\section{Analysis of data}

Statistical significance between the treatments was determined using one way ANOVA and Bonferroni's post-hoc test was applied for multiple comparisons wherever necessary. The Student's' $t$ ' test was used for biochemical estimations. The Solo 4 Statistical Package (BMDP Statistical Software Inc., Los Angeles, CA, USA) was used for data analysis.

\section{Results}

The results of wound contraction, mean wound healing time and biochemical estimations are expressed as Mean \pm SEM (Standard Error of Mean) in Table 1-2 \& Figures 1-10).

Table 1: Effect of different doses of Mimosa pudica ethanol extract (MPE) on various biochemical parameters in the regenerating wounds of mice at different post wounding days.

\begin{tabular}{|c|c|c|c|c|c|c|c|c|}
\hline \multirow{3}{*}{$\begin{array}{c}\text { MPE } \\
\text { (mg/kg b. } \\
\text { wt.) }\end{array}$} & \multicolumn{8}{|c|}{$\mathrm{Mg} / \mathrm{g}$ Dry Tissue Weight \pm Standard Error of the Mean } \\
\hline & \multicolumn{2}{|c|}{ Collagen } & \multicolumn{2}{|c|}{ Hexosamine } & \multicolumn{2}{|c|}{ DNA } & \multicolumn{2}{|c|}{ Nitic Oxide } \\
\hline & 7 Days & 12 Days & 7 Days & 12 Days & 7 Days & 12 Days & 7 Days & 12 Days \\
\hline 0 (CMC) & $32.33 \pm 0.88$ & $20.66 \pm 1.76$ & $10.66 \pm 0.33$ & $8.33 \pm 0.33$ & $4.51 \pm 0.22$ & $3.74 \pm 0.08$ & $19.00 \pm 1.15$ & $18.66 \pm 0.66$ \\
\hline 50 & $35.66 \pm 0.33^{\square}$ & $23.66 \pm 0.66$ & $13.33 \pm 0.33^{\square}$ & $10.66 \pm 0.33^{\square}$ & $4.67 \pm 0.5$ & $3.97 \pm 0.08$ & $17.33 \pm 0.44$ & $16.50 \pm 0.50^{*}$ \\
\hline 100 & $38.66 \pm 0.88^{\square}$ & $24.00 \pm 1.15$ & $14.66 \pm 0.88^{\square}$ & $12.66 \pm 0.66^{\square}$ & $5.63 \pm 0.46^{*}$ & $4.88 \pm 0.02^{\square}$ & $16.66 \pm 0.88$ & $15.50 \pm 0.50^{\square}$ \\
\hline 150 & $42.00 \pm 1.52^{\square}$ & $27.33 \pm 0.88^{\square}$ & $16.66 \pm 0.33^{\square}$ & $15.33 \pm 0.33^{\square}$ & $6.63 \pm 0.55^{\circledR}$ & $5.89 \pm 0.26^{\square}$ & $13.83 \pm 0.16^{\square}$ & $12.83 \pm 0.16^{\square}$ \\
\hline 200 & $47.33 \pm 0.66^{\square}$ & $31.33 \pm 0.88^{\square}$ & $18.33 \pm 0.66^{\square}$ & $16.33 \pm 0.66^{\square}$ & $7.20 \pm 0.31^{\square}$ & $6.22 \pm 0.15^{\square}$ & $12.50 \pm 0.28^{\Xi}$ & $11.66 \pm 0.16^{\text {区 }}$ \\
\hline
\end{tabular}

${ }^{*}=\mathrm{P}<0.05 ;{ }^{\circledR} \mathrm{P}<0.01 ;{ }^{\circledR} \mathrm{P}<0.001 ;{ }^{\circledR} \mathrm{P}<0.0001$ and No symbols: Non-significant. When compared to carboxymethylcellulose CMC group (0mg).

\section{Wound contraction}

Periodical estimation of wound contraction by recording the wound area provides a correct measure of wound repair and regeneration. Area of each wound at a specific time has been expressed as the percentage of its original size on day one (Figure 1). The mean corresponding area of wound for each group is plotted as a function of days after wounding (Figure 1). Measurements of wound areas regularly revealed that the rate of wound contraction of excision wound progressed with time and the untreated wound completely closed by day 24 (Figure 1). Treatment of mice with different doses of MPE resulted in the enhancement in wound contraction in a dose dependent manner (Figure 1). The wound contraction was almost similar to that of CMC treatment when the animals were treated with the lowest dose of $50 \mathrm{mg} / \mathrm{kg}$ until 9 days post-treatment, thereafter the wound contraction was greater and complete wound healing was achieved by day 22. A further increase in the MPE dose to $100 \mathrm{mg} /$ $\mathrm{kg}$ accelerated the wound healing however, complete closure of wound was achieved by day 22 similar to that of $50 \mathrm{mg} / \mathrm{kg}$ MPE. 
When the dose of MPE was increased up to 150 and $200 \mathrm{mg} / \mathrm{kg}$ the wound regeneration increased as indicated by a higher wound contraction and the complete closure of wound was affected by 20 and 18 days, respectively (Figure 1).

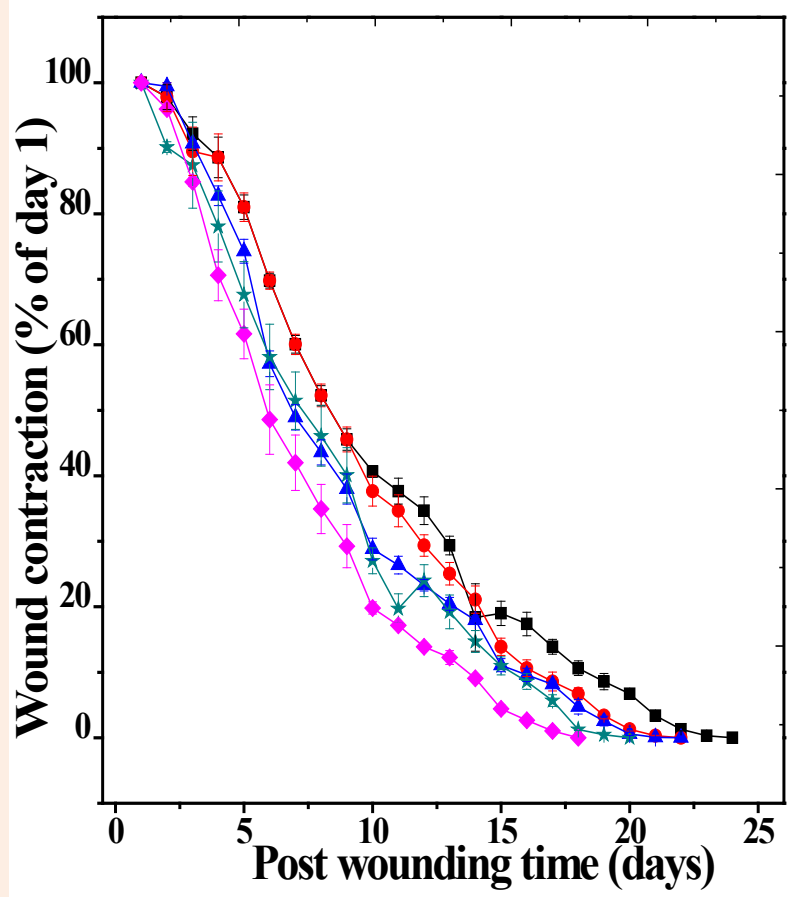

Figure 1: Acceleration of wound contraction by different doses of ethanol extract of Mimosa pudica (MPE) in the Swiss albino mice inflicted with deep dermal excision wound.

Squares: CMC; Circles: 50mg/kg MPE; Triangles: 100mg/kg MPE; Stars: $150 \mathrm{mg} / \mathrm{kg}$ MPE and Diamonds: $200 \mathrm{mg} / \mathrm{kg}$ MPE.

\section{Mean wound healing time}

The steady contraction of wound with time leads to complete contraction and healing of the wound. Regular monitoring of wound was carried out visually and the day on which wounds healed completely was recorded. The regular monitoring of excision wound showed a dose dependent reduction in the mean wound healing time (Figure 2). The mean wound healing time for CMC treated group was 24 days which declined with MPE treatment and animals receiving $50 \mathrm{mg} / \mathrm{kg}$ showed a mean wound healing time of 22 days (Figure 2). The increase in the MPE dose to $100 \mathrm{mg}$ further reduced the mean wound healing time, where it was 21 days. The greatest reduction in mean wound healing time was recorded for $200 \mathrm{mg} / \mathrm{kg}$ where it was 18 days, a reduction of 6 days when compared to CMC treatment (Figure 2).

\section{Biochemical profile}

The results of various parameters are shown in the Tables 1-2 \& Figures 3-10.

\section{Collagen synthesis}

The synthesis of collagen increased in a dose dependent manner on both day 7 and 12 post wounding (Figure 3). The lowest but significant $(\mathrm{p}<0.01)$ increase was recorded on day 7 post wounding in the mice treated with $50 \mathrm{mg} / \mathrm{kg}$ b. wt. MPE. With increasing dose, the synthesis of neocollagen also increased and a maximum rise in collagen synthesis was observed for the $200 \mathrm{mg} /$ $\mathrm{kg}$ b. wt. MPE on day 7 post wounding (Figure 3). The estimation of collagen synthesis on 12 day post wounding showed a decline in the rate of collagen synthesis when compared to day 7 and significant increases were only observed for 150 and $200 \mathrm{mg} / \mathrm{kg}$ MPE (Table 1).

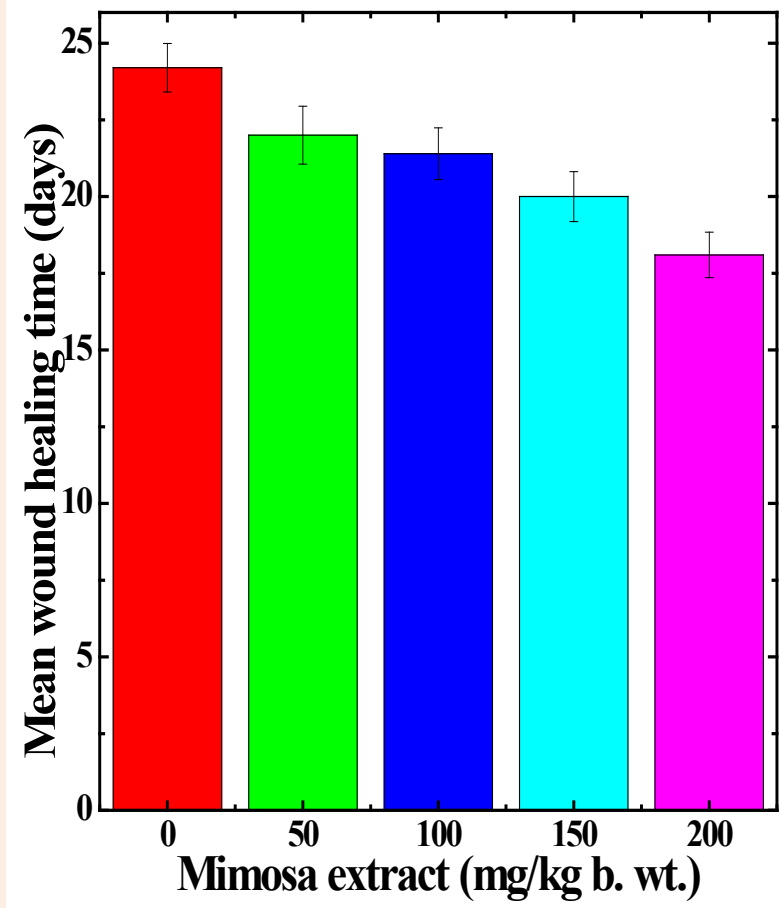

Figure 2: Augmentation in the mean wound healing time of deep dermal excision wound of mice treated with different doses of ethanol extract of Mimosa pudica.

\section{Hexosamine synthesis}

Hexosamine synthesis in the regenerating wound also increased in dose dependent manner on both day 7 and 12 post wounding (Figure 4). The treatment of mice with different doses of MPE caused a significant rise in the hexosamine synthesis on both day 7 and 12 posts wounding (Table 1). The hexosamine synthesis declined with time and the rate of hexosamine synthesis was lower on day 12 when compared to day 7 post wounding (Figure 4). A maximum syhtesis of hexosamine was recorded for $200 \mathrm{mg} / \mathrm{kg}$ MPE on both day 7 and 12 post wounding (Figure 4).

\section{DNA synthesis}

The DNA synthesis estimation shows the proliferation status of cells and the DNA synthesis increased in a dose dependent manner at 7 and 12 day post wounding in the regenerating excision wounds of mice treated with different doses of MPE (Figure 5). The lowest doses of $50 \mathrm{mg} / \mathrm{kg}$ MPE was not very efficient in increasing the DNA synthesis as the increase was statistically non-significant on both 7 and 12 day post wounding (Table 1). However, further increases in MPE dose resulted in a significant 
rise in the DNA synthesis at both day 7 and 12 post wounding with a maximum elevation for $200 \mathrm{mg} / \mathrm{kg}$ MPE (Table 1)).

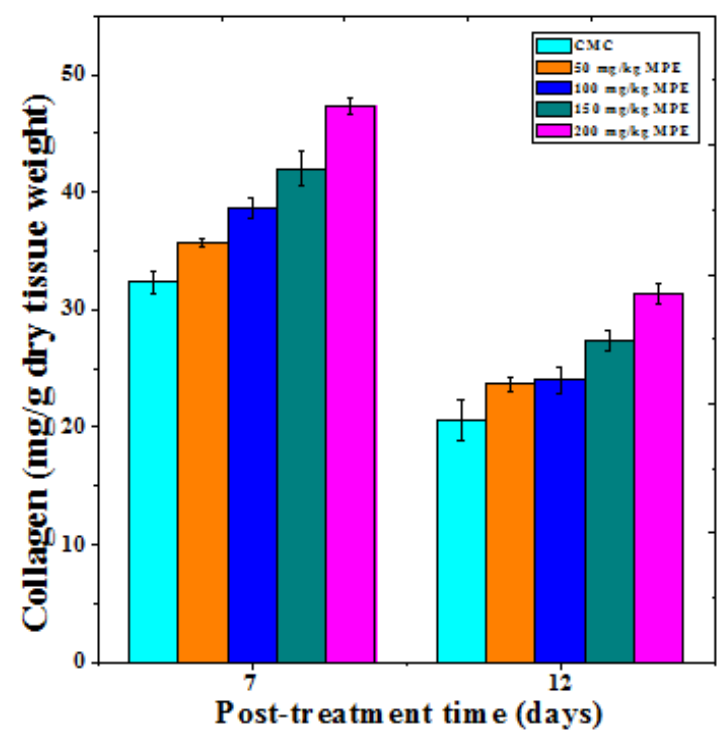

Figure 3: effect of different doses of ethanol extract of Mimosa pudica on the synthesis of collagen at different post wounding days in mice inflicted with deep dermal excision wound.

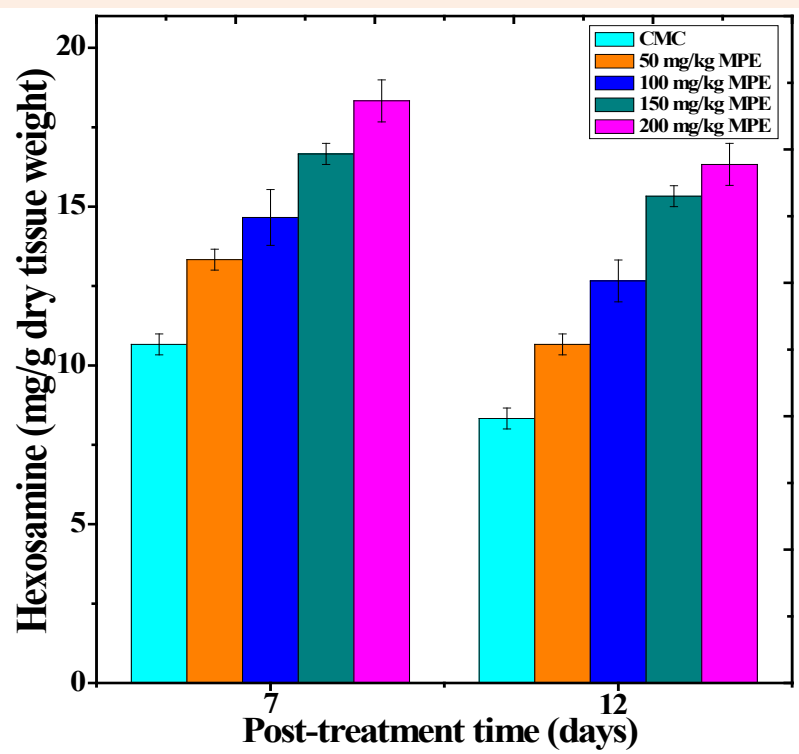

Figure 4: Effect of different doses of ethanol extract of Mimosa pudica on the hexosamine synthesis at different post wounding days in mice inflicted with deep dermal excision wound.

\section{Nitric oxide synthesis}

The nitric oxide production increased in a dose dependent manner in the regenerating excision wounds of mice receiving different doses of MPE at both 7 and 12 days post wounding (Figure 6). The increase in nitric oxide was non-significant on day 7 post wounding in the mice treated with 50 and $100 \mathrm{mg} / \mathrm{kg} \mathrm{b}$. wt. of MPE. However a further increase in MPE dose resulted in a significant rise in the NO production on day 7 post wounding (Table 1). The rise in NO production was significantly higher for all MPE doses on day 12 Post wounding (Table 1).

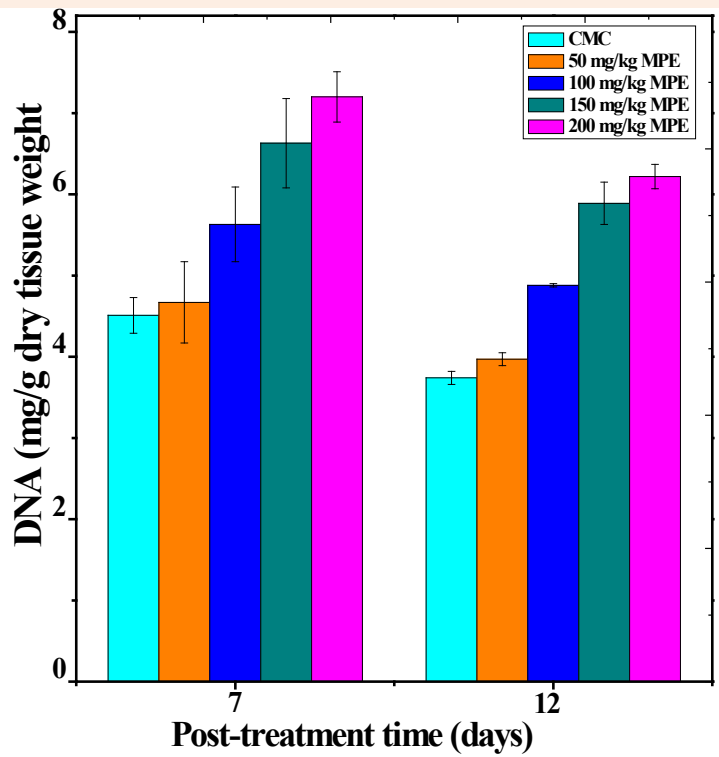

Figure 5: Effect of different doses of ethanol extract of Mimosa pudica on the DNA synthesis at different post wounding days in mice inflicted with deep dermal excision wound.

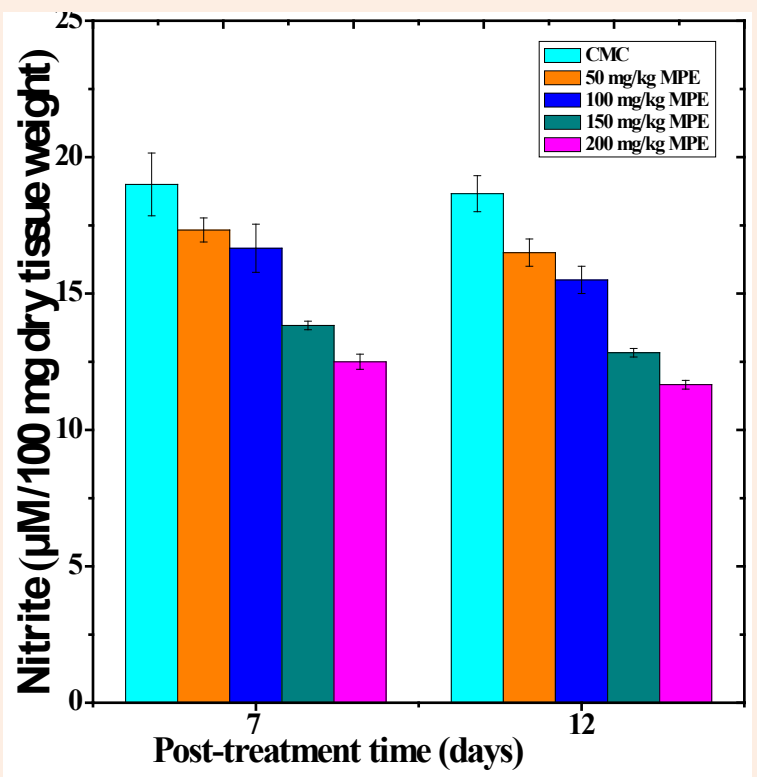

Figure 6: Effect of different doses of ethanol extract of Mimosa pudica on the nitric oxide synthesis at different post wounding days in mice inflicted with deep dermal excision wound. 


\section{Estimation of antioxidants}

\section{Glutathione}

The glutathione concentration in wound granulation tissue of untreated mice was $0.77 \pm 0.02$ and $1.06 \pm 0.05 \mu \mathrm{moles} / \mathrm{mg}$ of protein at day 7 and day 12 post wounding, respectively (Table 2). The administration of MPE resulted in a time and dose-dependent increase in the GSH concentration in the wound granulation tissue (Figure 7). This increase in GSH concentration was significantly higher than the untreated control (Table 2). A maximum rise in GSH concentration was observed at 7 and 12 days post wounding at a dose of $200 \mathrm{mg} / \mathrm{kg} \mathrm{b}$. wt. MPE treatment (Figure7).

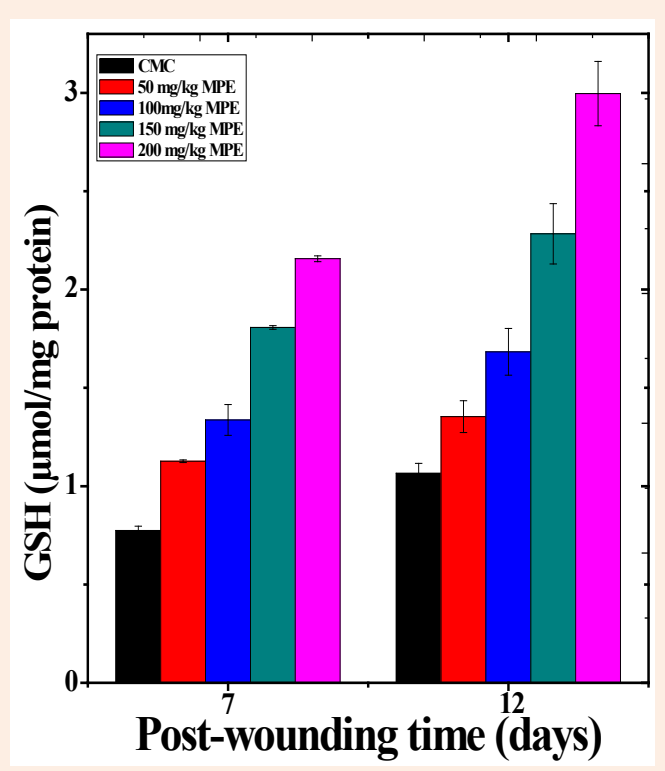

Figure 7: Effect of different doses of ethanol extract of Mimosa pudica on the glutathione contents at different post wounding days in mice inflicted with deep dermal excision wound.

\section{Catalase}

The base line catalase activity in wound granulation tissue of untreated mice was $5.70 \pm 0.12$ and $5.5 \pm 0.14 \mathrm{U} / \mathrm{mg}$ protein at day 7 and day12 post-wounding, respectively (Table 2). The administration of MPE caused a time and dose-dependent but significant rise in the catalase activity of wound granulation tissue (Figure $8 \&$ Table 2). A maximum rise in catalase activity was observed at 7 and 12 days post-wounding in the granulation tissue of mice receiving $200 \mathrm{mg} / \mathrm{kg}$ b. wt. MPE treatment (Figure 8).

\section{Superoxide dismutase}

The base line SOD activity in the regenerating wound granulation tissue of untreated mice was $13.98 \pm 0.93$ and $14.22 \pm 0.2 \mathrm{U} / \mathrm{mg}$ protein at day 7 and day12 post wounding, respectively (Table 2). The administration of MPE before wound creation resulted in a time and dose-dependent increase in the SOD activity in the wound granulation tissue (Figure 9). This increase in SOD concentration was significantly higher than untreated control (Table 2). The treatment of mice with $200 \mathrm{mg}$ / $\mathrm{kg}$ MPE before wounding showed a greatest rise in SOD activity at both 7 and 12 days post wounding (Figure 9).

\section{Lipid peroxidation}

The lipid peroxidation (LOO) in wound granulation tissue of regenerating wound of untreated mice was $0.58 \pm 0.02$ and $0.55 \pm 0.01 \mathrm{MDA} \mathrm{nM} / \mathrm{mg}$ protein at day 7 and 12 post-wounding, respectively (Table 2). Treatment of mice with different doses of MPE before infliction of deep dermal excision wound resulted in a dose-dependent but significant decrease in the LOO of wound granulation tissue at both the post wounding times (Figure 10 and Table 2). The LOO was higher on 7 days post wounding than that of day 12 (Figure 10). The MPE administration reduced the LOO greater on 12 days when compared to day 7 post wounding and the decline in LOO was highest in the mice receiving $200 \mathrm{mg} /$ $\mathrm{kg}$ b.wt. MPE when compared to the other doses (Figure 10).

Table 2: Effect of different doses of Mimosa pudica ethanol extract on various antioxidants in the regenerating wounds of mice at different post wounding days.

\begin{tabular}{|c|c|c|c|c|c|c|c|c|}
\hline \multirow{2}{*}{$\begin{array}{c}\text { MPE } \\
\text { (mg/kg } \\
\text { b. wt.) }\end{array}$} & \multicolumn{2}{|c|}{ GSH ( $\mu \mathrm{mol} / \mathrm{mg}$ Protein) } & \multicolumn{2}{|c|}{ Catalase (U/mg Protein) } & \multicolumn{2}{|c|}{$\begin{array}{l}\text { Superoxide Dismutase } \\
\text { (U/mg Protein) }\end{array}$} & \multicolumn{2}{|c|}{$\begin{array}{l}\text { Lipid Peroxidation MDA } \\
\text { (nM/mg Protein) }\end{array}$} \\
\hline & 7 Days & 12 Days & 7 Days & 12 Days & 7 Days & 12 Days & 7 Days & 12 Days \\
\hline $\mathrm{CMC}(0)$ & $0.77 \pm 0.02$ & $1.06 \pm 0.05$ & $5.70 \pm 0.12$ & $5.5 \pm 0.141$ & $13.98 \pm 0.93$ & $14.22 \pm 0.20$ & $0.58 \pm 0.02$ & $0.55 \pm 0.01$ \\
\hline 50 & $1.12 \pm 0.01^{\square}$ & $1.35 \pm 0.08^{\square}$ & $6.02 \pm 0.12^{\square}$ & $7.32 \pm 0.04^{\square}$ & $17.70 \pm 0.36^{\square}$ & $18.96 \pm 0.42^{\square}$ & $0.52 \pm 0.01^{*}$ & $0.50 \pm 0.01^{*}$ \\
\hline 100 & $1.34 \pm 0.08^{\llbracket}$ & $1.68 \pm 0.11^{\square}$ & $6.31 \pm 0.22^{\llbracket}$ & $8.08 \pm 0.16^{\text {日 }}$ & $21.20 \pm 0.55^{\square}$ & $21.73 \pm 0.96^{\square}$ & $0.48 \pm 0.01^{\square}$ & $0.45 \pm 0.01^{\square}$ \\
\hline 150 & $1.80 \pm 0.01^{\square}$ & $2.28 \pm 0.15^{\square}$ & $6.99 \pm 0.09^{\square}$ & $8.10 \pm 0.30^{\square}$ & $34.83 \pm 0.88^{\varpi}$ & $35.88 \pm 0.74^{\square}$ & $0.46 \pm 0.01^{\square}$ & $0.42 \pm 0.01^{\text {曰 }}$ \\
\hline 200 & $2.15 \pm 0.01^{\square}$ & $2.99 \pm 0.16^{\natural}$ & $8.42 \pm 0.30^{\square}$ & $9.08 \pm 0.05^{\square}$ & $42.95 \pm 0.45^{\square}$ & $43.42 \pm 0.43^{\square}$ & $0.43 \pm 0.01^{\square}$ & $0.39 \pm 0.01^{\square}$ \\
\hline
\end{tabular}

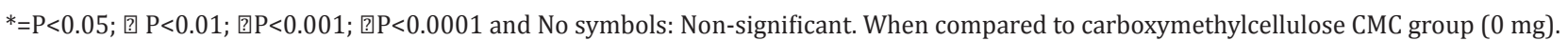

\section{Discussion}

Plants and herbs have been used to treat numerous ailments in human beings since the advent of human history and several medicinal systems like Ayruveda and Chinese have been using mainly natural products to treat different diseases in humans. These remedies are time tested and used for several generations without untoward side effects. The effectiveness of medicinal plants in human healthcare may be due their ability to synthesize different phytochemicals for their various metabolic needs or otherwise [5]. The use of whole extract will contain all these phytochemicals and will provide maximum curability with no untoward side effects [27]. The present study was undertaken to explore the wound healing activity of lajwanti i.e. Mimosa pudica in the Swiss albino mice inflicted with deep dermal excision wound. 


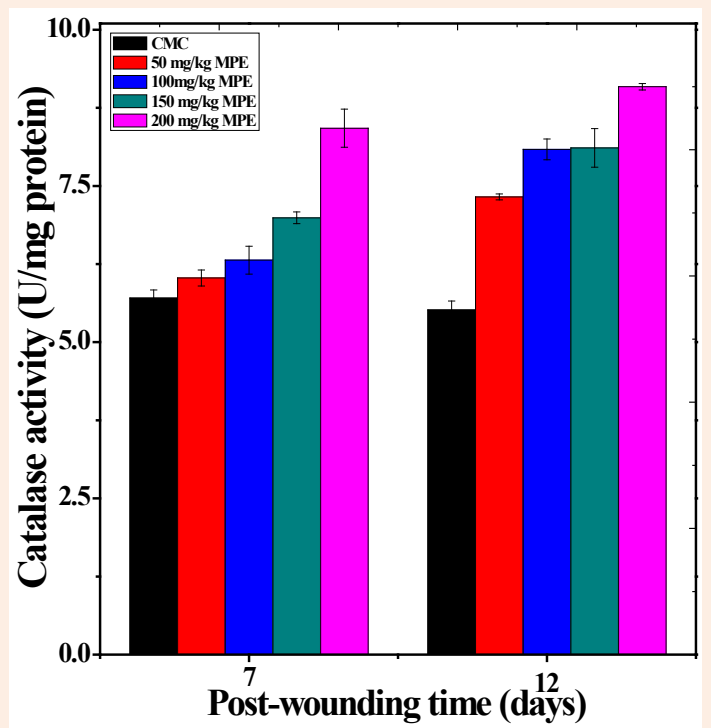

Figure 8: Effect of different doses of ethanol extract of Mimosa pudica on the catalase activity at different post wounding days in mice inflicted with deep dermal excision wound.

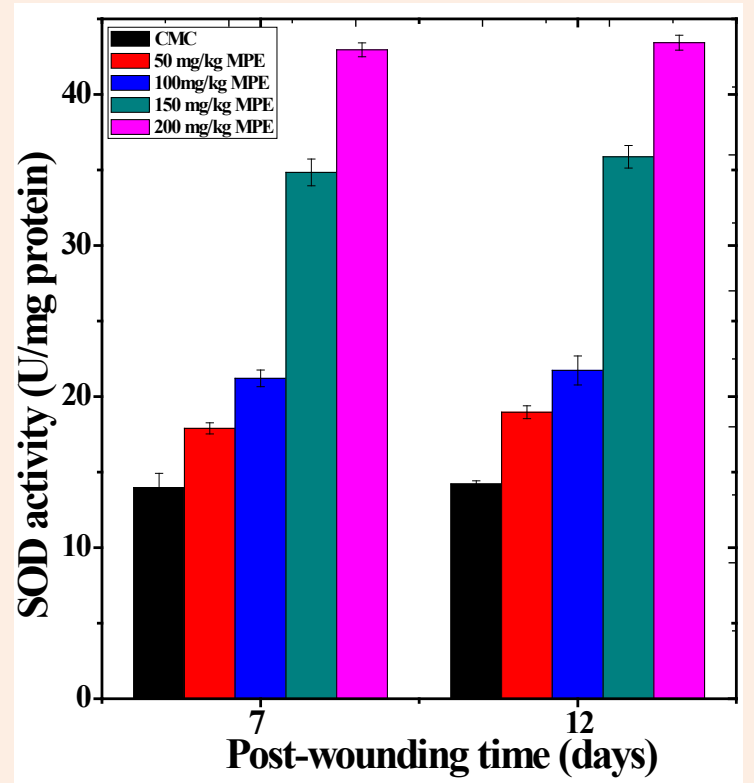

Figure 9: Effect of different doses of ethanol extract of Mimosa pudica on the superoxide dismutase activity at different post wounding days in mice inflicted with deep dermal excision wound.

Wound healing is an intricate process that progresses in a predefined but orderly manner. It involves the cooperation and coordination of various types of cells which are present in the wound bed or recruited from the margins of the wound and the endothelial system to direct the healing. The process of wound healing usually includes three physiological responses that include inflammation, regeneration and wound remodeling. The inflammation is the immediate response after wounding and is essential to recruit other cells that play a crucial role in the healing process [28]. The inflammatory phase in initiated by migration of neutrophils, monocytes and macrophages into the wound bed and their presence initiate debridement and secretion of many cytokines required for the proper healing of the wound [9].

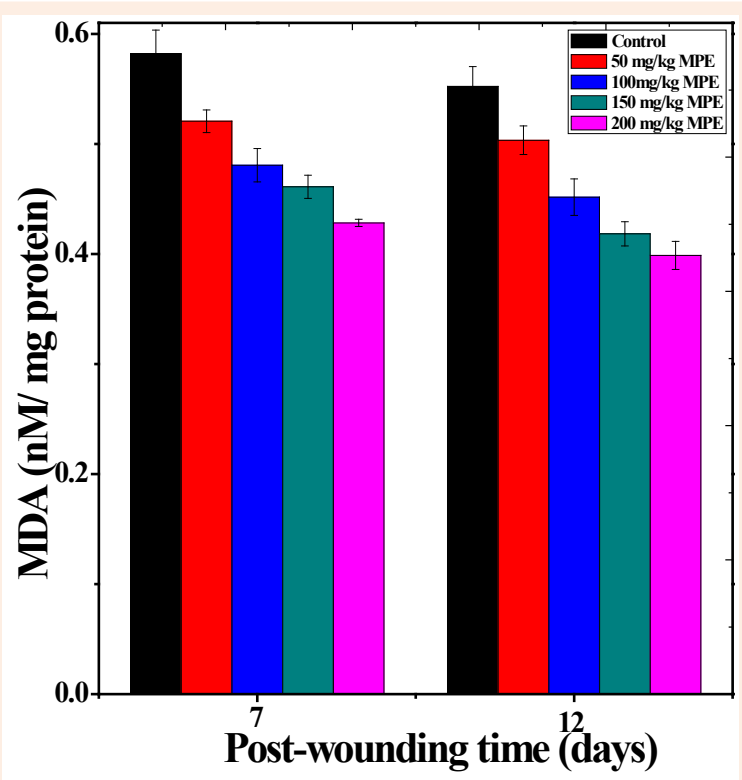

Figure 10: Effect of different doses of ethanol extract of Mimosa pudica on the lipid peroxidation at different post wounding days in mice inflicted with deep dermal excision wound.

The main aim of the injured tissue is to heal the wound as early as possible to avoid other detrimental consequences as a result the new tissue is not the exact replica of the original uninjured tissue [29]. This restoration of the tissue is due to the concerted action of blood platelets, neutrophils, monocytes/ macrophages, endothelial cells fibroblasts, and keratinocytes [9]. In normal course the wound would heals itself but the use of medicine may help the tissue by favourably modulating different regenerative responses and subsequently reducing the defects. The administration of different doses of lajwanti ethanol extract increased the wound repair and regeneration in a dose dependent manner and $200 \mathrm{mg} / \mathrm{kg}$ MPE accelerated the process of wound healing to the maximum extent as indicated by the increased wound contraction and shortest wound healing time. The periodic measurement of the wound area gives a fairly good indication of wound contraction and the repair status of the wound. As the wound contracts the wounded area shrinks with time and the complete closure of the wound is effected $[18,27,30$ 34]. The reports regarding the use of ethanol extract of whole lajwanti plant on the healing of deep dermal excision wound in mice are unavailable. However, earlier studies have reported increased reduction in the wound area after topical application of ethanol or chloroform extract of leaves of lajwanti in rats [35,36]. Likewise, topical application of chloroform and methanol extracts of lajwanti roots on the excision wound of rats enhanced wound contraction and epithelialization [17]. A similar effect has been observed in wound contraction when the mice were administered with ascorbic acid, curcumin, Nigella sativa extract or topically applied with curcumin [27,30-34]. 
The contraction of wound is caused by the concerted action of contractile myofiborblasts, which are generated as a result of migration of fibroblasts from the unaffected dermis and subcutaneous tissue into the center of the wound granulation tissue and acquire microfibrils, especially the contractile actin and are converted into myofibroblasts. These myofibroblasts usually disappears by apoptosis once the wound heals completely. Their persistence may lead to pathologic condition during wound healing [37-39]. The administration of MPE would have triggered the recruitment of more fibroblasts from wound edges and their conversion into myofibrobalsts leading to greater contraction and early healing of wounds in this group when compared to normal untreated control group. This may have subsequently reduced the mean wound healing time in MPE treated group.

The extracellular matrix (ECM) containing fibronectin, integrins, glycosaminoglycans, proteoglycans, thrombospondins, tenascin, vitronectin, and collagens play a major role in maintaining the structural integrity during wound healing [40]. They help in cell migration, storage, and delivery of growth factors and various cytokines to the wound bed [41]. The collagens are most important and abundant proteins among ECM and their main function is cell adhesion, cell migration, tissue morphogenesis, tissue scaffolding, and tissue repair. These are fibrillar proteins present in the dermis, which provide structural support to the cells and regulate inflammatory reaction [41] Estimation of collagen has shown that MPE increased its synthesis in a dose dependent manner. There are no reports regarding the enhanced synthesis of collagen by lajwanti. However, ascorbic acid, curcumin and Nigella sativa have been shown to increase the synthesis of collagen, hexosamine and DNA in the regenerating excision wounds of mice $[18,27,30,31]$. The enhanced hexosamine synthesis in the regenerating wounds receiving MPE may be responsible for providing higher strength to the wounds. The topical application of $L$. japonica has been reported to increase collagen and hexosamine syntheses in the regenerating excision wounds of rats earlier [42]. The DNA synthesis is linked to cell proliferation and increased DNA synthesis by MPE may have increase the proliferation of different cells like fibroblasts and keratinocytes leading to the early healing of the regenerating wound in the present study [18,27,31-34]. Inflammation is an early event in the healing of regenerating wounds and nitric oxide estimation at day 7 and 12 post wounding has shown that MPE administration reduced the inflammatory response on these days indicating the progression of regeneration and early closure of the wound.

The reactive oxygen species (ROS) are required during wound healing, especially during early stages as they stimulate cell signaling, especially the vascular endothelial growth factor (VEGF) in keratinocytes accelerates angiogenesis and early healing $[43,44]$. However, excess of ROS may have adverse impact on wound healing and they shall be neutralized. The MPE has reduced lipid peroxidation a marker of oxidative stress after wounding and also elevated the glutathione concentration, catalase and superoxide dismutase activity. The ascorbic acid, curcumin and Nigella sativa extract have been reported to elevate GSH, and GSHpx and superoxide dismutase in the regenerating excision wounds of mice earlier $[18,27,30,45]$

The exact mechanism of action of lajwanti extract in accelerating the repair and regeneration of wound healing is not clearly understood and the mechanism for increased contraction and reduced mean wound healing time may be several. The MPE has increased the synthesis of collagen, hexosamine and DNA, which are essential components of wound healing. The alleviation of excess free radicals produced in the excision wound by MPE may be another mechanism of enhanced wound healing. This is supported by the increased GSH concentration and activities of catalase and SOD enzymes and reduction in the lipid peroxidation. Wounding activates the expression of NF$\kappa \mathrm{B}$ as early as $1 / 2$ hour after wounding and it is essential to elicit proinflammatory responses required for cell proliferation in the regenerating wounds [46]. The presence of MPE before wounding may have activated NF- $\kappa$ B immediately after wounding however; it may not have allowed its persistence activation, which could have detrimental effect on healing of wounds. The MPE may have also triggered the synthesis of, PDGF, TGF- $\beta$, VEGF and other cytokines that are essential for wound healing leading to the early regeneration and repair of the wounds. The increased level of antioxidants suggests that MPE may have stimulated Nrf2 signaling as a late event leading to early repair of the excision wounds as the activation of Nrf2 signaling has been reported to reduce excess inflammation during repair and regeneration of the wound [47]. The increase in wound healing activity may due to the presence of flavonoids including quercetin, leuteolin, and rutin and other phytochemicals like mimosine in the MPE [12].

The present study demonstrates that MPE increased the wound contraction in a dose dependent manner and at the same time reduced the mean wound healing time. This acceleration in wound contraction may be due to increased collagen, hexosamine and DNA syntheses and reduced NO synthesis. The other mechanism may be increased antioxidant status at later times that wound have increased the cell proliferation and effected early wound healing. It is also possible that MPE may have stimulated molecular mechanisms where it may have activated the NF$\kappa b$, TGF- $\beta$, PDGF, VGEF and other cytokines as an early event. However it may have also activated Nrf2 as a late event to subdue the inflammatory reactions, which are not required during late stages of wound healing.

\section{Acknowledgements}

This work was carried out under a Grant from University Grants, Government of India, New Delhi to Prof. GCJ.

\section{Conflict of Interest}

None.

\section{References}

1. Ekor M (2014) The growing use of herbal medicines: issues relating to adverse reactions and challenges in monitoring safety. Front Pharmacol 4: 177.

2. Ernst E (2005) The efficacy of herbal medicine -an overview. Fundam Clin Pharmacol 19(4): 405-409.

3. Eisenberg D, David RB, Ettner SL, Appel S, Wilkey S, et al. (1998) Trends in alternative medicine use in the United States; 1990-1997: results of a follow-up national survey. JAMA 280(18): 1569-1575.

4. Newman DJ, Cragg GM (2016) Natural Products as Sources of New Drugs from 1981 to 2014. J Nat Prod 79(3): 629-661. 
5. Shantabi L, Jagetia GC, Vabeiryureilai M, Lalrinzuali K (2014) Phytochemical Screening of Certain Medicinal Plants of Mizoram, India and their Folklore Use. J Biodiver Bioprospect Dev 1: 4.

6. Leaper DJ, Harding KG (1998) Wounds: biology and management. In: Shaw TJ \& Martin P (Eds.), Oxford University Press, USA.

7. Shaw TJ, Martin P (2009) Wound repair at a glance. J Cell Sci $122(\mathrm{Pt}$ 18): 3209-3213.

8. Velnar T, Bailey T, Smrkolj V (2009) The wound healing process: an overview of the cellular and molecular mechanisms. J Int Med Res 37(5): 1528-1542.

9. Sinno H, Prakash S (2013) Complements and the Wound Healing Cascade: An Updated Review. Plastic Surg Int 146764.

10. Balick M, Cox PA (1996) Plants, People and Culture: the Science of Ethnobotany; Scientific American Library. W.H. Freeman and Company, New York, USA.

11. Suh DD, Schwartz IP, Canning DA, Snyder HM, Zderic SA, et al. (1998) Comparison of dermal and epithelial approaches to laser tissue soldering for skin flap closure. Lasers Surg Med 22(5): 268-274.

12. Sanaye MM, Joglekar CS, Pagare NP (2015) Mimosa- A brief overview. J Pharmacog Phytochem 4(2): 182-187.

13. Chauhan BS, Johnson DE (2009) Germination, emergence and dormancy of Mimosa pudica. Weed Biol Managem 9(1): 38-45.

14. Zaware BB, Chaudhari SR, Shinde MT (2014) An Overview of Mimosa pudica linn. : Chemistry and Pharmacological Profile. Res J Pharmaceut Biol Chem Sci 5(6): 754-761.

15. Muhammad G, Hussain MA, Jantan I, Bukhari SNA (2016) Mimosa pudica L., a high-value medicinal plant as a source of bioactives for pharmaceuticals. Compreh Rev Food Sci Food Safety 15(2): 303-315.

16. Bum EN, Dawack DL, Schmutz M, Rakotonirina A, Rakotonirina SV, et al. (2004) Anticonvulsant activity of Mimosa pudica decoction. Fitoterapia 75(3-4): 309-314.

17. Paul J, Khan S, Asdaq SMB (2010) Wound healing evaluation of chloroform and methanolic extracts of Mimosa Pudica roots in rats. Int J Biol Med Res 1(4): 223-227.

18. Jagetia GC, Rajanikant GK, Rao KVNM (2003) Modulation of radiation-induced delay in the wound healing by ascorbic acid in mice hemi-body exposed to different doses of $\gamma$-radiation. Wounds 15(10): 324-338

19. Woessner JF (1961) The determination of hydroxyproline in tissues and protein samples containing small proportions of this amino acid. Arch Biochem Biophy 93: 440-447.

20. Elson LA, Morgan WT (1933) A colorimetric method for the determination of glucosamine and chondrosamine. Biochem J 27(6): 1824-1828.

21. Burton K (1956) A study of the conditions and mechanism of the diphenylamine reaction for the colorimetric estimation of deoxyribonucleic acid. Biochem J 62(2): 314-323.

22. Hevel JM, Marletta MA (1994) Nitric-oxide synthase assays. Methods Enzymol 233: 250-258.

23. Moron MS, Depierre JW, Mannervik B (1979) Levels of glutathione, glutathione reductase and glutathione S-transferase activities in rat lung and liver. Biochim Biophy Acta 582(1): 67-78.

24. Aebi H (1984) Catalase in vitro. Methods Enzymol 105: 121-126.
25. Ewing JF, Janero DR (1995) Microplate superoxide dismutase assay employing a nonenzymatic superoxide generator. Anal Biochem 232(2): 243-248.

26. Gelvan D, Saltman P (1990) Different cellular targets of $\mathrm{Cu}$ - and Fecatalyzed oxidation observed using a $\mathrm{Cu}$-compatible thiobarbiturate acid assay. Biochimica Biophysica Acta 1035(3): 353-360.

27. Jagetia GC, Ravikiran PB (2015) Acceleration of Wound Repair and Regeneration by Nigella sativa in the Deep Dermal Excision Wound of Mice Whole Body Exposed to Different Doses of $\gamma$-radiation. Am Res J Med Surg 1(3): 1-17.

28. Pang C, Ibrahim A, Bulstrode NW, Ferretti P (2017) An overview of the therapeutic potential of regenerative medicine in cutaneous wound healing. Int Wound J 14(3):450-459.

29. Stramer BM, Mori R, Martin P (2007) The inflammation-fibrosis link? A Jekyll and Hyde role for blood cells during wound repair. J Invest Dermatol 127(5): 1009-1017.

30. Jagetia GC, Rajanikant GK, Rao SK, Baliga MS (2003) Alteration in the glutathione, glutathione peroxidase, superoxide dismutase and lipid peroxidation by ascorbic acid in the skin of mice exposed to fractionated $\gamma$-radiation. Clin Chim Acta 332(1-2): 111-121.

31. Jagetia GC, Rajanikant GK (2004) Role of curcumin, a naturally occurring phenolic compound of turmeric in accelerating the repair of excision wounds in mice whole-body exposed to various doses of $\gamma$-radiation. J Surg Res 120(1): 127-138

32. Jagetia GC, Rajanikant GK (2005) Curcumin treatment enhances the repair and regeneration of wounds in mice hemi-body exposed to $\gamma$ -radiation. Plastic Reconstruct Surg 115(2): 515-528.

33. Jagetia GC Rajanikant GK (2012) Acceleration of wound repair by curcumin in the excision wound of mice exposed to different doses of fractionated $\gamma$-radiation. Int Wound J 9(1): 76-92.

34. Jagetia GC, Rajanikant GK (2017) Topical application of curcumin augments healing of deep dermal excision wound of mice exposed to whole-body gamma radiation. J Nur Healthcare 2(1).

35. Singh MP, Bharghava S, Bhaduaria RS, Sharma CS (2010) Wound Healing Potential of Alcoholic Extract of Mimosa pudica Linn. Leaves. Pharmacologyonline 2: 32-38.

36. Venkateshwarlu G, Vijayabhaskar K, Pavankumar G, Kirankumar P, Harishbabu K, et al. (2011) Wound healing activity of Mimosa pudica in albino Wistar rats. J Chem Pharm Res 3(5): 56-60.

37. Gabbiani G (2004) The Evolution of the Myofibroblast Concept: a Key Cell for Wound Healing and fibrotic diseases. I processi di riparazione e fibrosis. G Gerontol 52: 280-282.

38. Darby IA, Laverdet B, Bonté F, Desmoulière A (2014) Fibroblasts and myofibroblasts in wound healing. Clin Cosmet Investigat Dermatol 7: 301-311

39. Bochaton-Piallat M-L, Gabbiani G, Hinz B (2016) The myofibroblast in wound healing and fibrosis: answered and unanswered questions. F1000Res 5. pii: F1000.

40. Olczyk P, Mencner Ł, Komosinska-Vassev K (2014) The Role of the Extracellular Matrix Components in Cutaneous Wound Healing. BioMed Res Int 747584.

41. Xue M, Jackson CJ (2015) Extracellular Matrix Reorganization During Wound Healing and Its Impact on Abnormal Scarring. Adv Wound Care 4(3): 119-136. 
42. Chen WC, Liou SS, Tzeng TF, Lee SL, Liu IM (2012) Wound repair and anti-inflammatory potential of Lonicera japonica in excision woundinduced rats. BMC Complement Altern Med 12: 226.

43. Sen CK, Khanna S, Babior BM, Hunt TK, Ellison EC, et al. (2002) Oxidant-induced vascular endothelial growth factor expression in human keratinocytes and cutaneous wound healing. J Biol Chem 277(36): 33284-33290.

44. Kurahashi T, Fujii J (2015) Roles of antioxidative enzymes in wound healing. J Dev Biol 3: 57-70.
45. Jagetia GC, Rajanikant GK (2015) Curcumin Stimulates the Antioxidant Mechanisms in Mouse Skin Exposed to Fractionated $\gamma$ -Irradiation. Antioxidants 4(1): 25-41.

46. Heng M (2017) Phosphorylase Kinase Inhibition Therapy in Burns and Scalds. BioDiscovery 20: e11207.

47. Ambrozova N, Ulrichova J, Galandakova A (2017) Models for the study of skin wound healing. The role of Nrf2 and NF-кB. Biomed Pap Med Fac Univ Palacky Olomouc Czech Repub 161(1): 1-13. 